\title{
Recombinant Glucagon
}

National Cancer Institute

\section{Source}

National Cancer Institute. Recombinant Glucagon. NCI Thesaurus. Code C520.

The recombinant form of the endogenous polypeptide hormone Glucagon consisting of 29 amino acids responsible for the release of stored glucose, causing increased blood glucose levels. Clinical Use: Diagnostic Aid for Imaging Studies and Hypoglycemia. 